\title{
ICT USAGE IMPLEMENTATION IN ICT-BASED OPEN-DISTANT LEARNING A CASE STUDY AT OPEN SENIOR HIGH SCHOOL OF NARMADA
}

\author{
Kusnandar, Dwi Sumarwanto, and Supandri \\ Pustekkom Kemendikbud \\ JI. RE. Martadinata Km 15,5 Ciputat, Tangerang Selatan \\ Email: kusnandar@kemdikbud.go.id
}

\begin{abstract}
To improve Pendidikan Menengah Universal (Universal High Educatio) service, Education and Culture Ministry has been developing the program of SMA Terbuka Berbasis TIK (ICT-Based Open Senior High School) in 6 locations since 2014. This is a case study at one of the 5 locations, i.e. at SMA Terbuka Narmada, Lobok Barat, NTB. The question of this research is "How is the implementation of ICT usage in learning-teaching process at SMA Terbuka Narmada in mother school, in TKB, as well as student individual activities?". To answer the question, some steps are taken: collect initial data; literary review; field study; interview; and guided discussion. The result shows that the ICT usage to support the learning-teaching process at SMA Terbuka Narmada is good at the begining. Some fact about tablet computer which is the main learning gadget for the students are that 1) it has been equipped with Learning Management System developed by the mother school; 2) it has been filled with content and modules developed by the foster teachers; and 3) it has been carried out in two modes, online learning (students are at homes) as well as off-line learning (students are at TKB with their foster teacher). However, the continuous implementation of this system is somehow missing support from central management because of its inconsistency so that the learning-teaching process at TKB tends to be carried out in a convensional way again, i.e. face-to-face. It is recommended that 1) there should be consistent policy from the management (government); 2) there should be synergy among the central management, regional management, and education unit; and 3) the system, application, content, modules, and ICT-Based learningteacching process that have been developed by the mother school should be supported by the policy makers in central management level as well as in provincial level.
\end{abstract}

Key Words: Open Senior High School, ICT-Based, Tablet Computer, Learning Management System, Consistency 


\section{INTRODUCTION}

In 2014, the Ministry of Education and Culture through the PKLK Directorate launched an ICT (information and communication technology) -based open senior education service called SMA Terbuka (abbreviated; SMAT). This service aims to answer the needs of middle school age children who are not accommodated in regular high school for various reasons, including due to geographical location, demands for work, economic problems, choice of learning styles, or other problems. As a pilot, ICT-based SMAT is opened in 6 (six) locations, namely; SMAN 2 Padalarang, West Java, SMAN 1 Gambut Banjarmasin, South Kalimantan, SMAN 1 Kepanjen East Java, SMAN 1 Narmada West Lombok, SMAN 3 Sorong, West Papua, and SMAN 12 Merangin-Jambi.

Learning activities in the SMAT are designed based on ICT, therefore all the SMATs are facilitated by ICT devices which consist of tablets for each student who has installed the elearning application and a number of content material for learning materials, internet connections, and other support.

SMAT is one of the services within the framework of the universal secondary education movement. This movement aims to provide broadest access to junior high school students to be able to continue to further education. SMAT is one of the alternative services with a number of considerations, including the number of junior high school students who have not been able to be accommodated in regular high school, because; 1) Limited capacity of high school, 2) Geographical location of residence of prospective students who are far from high school available, 3) There are a number of prospective students who with a number of reasons must work to help their parents, they cannot participate in learning activities such as schooling generally. The choice of open-distance learning (ODL) is considered appropriate, especially to serve children who live in rural, coastal, island, and even busy cities even though the ODL is a relevant solution.

However, the implementation of ODL for teenagers is still has a number of questions that doubt its success. This is understandable considering that all this time teenagers are seen as still in development, not emotionally mature, have not been able to make their own choices, including not being able to manage their own affairs in learning, etc. In addition, in terms of certainty and continuity of open learning system services also still has a rest number of question marks. This, as suggested by Jaka Warsihna, for the implementation of the Act 1) prepared its legal umbrella, 2) conducted appropriate socialization, 3) the learning system was not entirely remote but blanded, 4) pioneering was needed before being applied on a wide scale.

The target of the SMA / $\mathrm{K}$ Open achievement is very optimistic. It is planned that in 20145 stubs will be opened, 2015 will be increased to 50 stubs, followed by 2016 will be doubled to 100 stubs, so that by the end of 2020 it is expected to be opened in a number of 300 main schools (Presentation of PKLK Directorate, 2014). 
However, over time, the development policy of Open Schools also began to fade. Even in the 5 stubs in 2014, they stumbled, where both management support and technical support decreased. This resulted in the parent school having to bear the burden of its own problems. They must find their own solutions so that this service continues. Service commitment to the public is not easy to just cut off in the middle of the road. This is one of the factors that led to our research.

\section{LITERATURE REVIEW}

Long distance open education for secondary schools was first introduced in Indonesia since 1979 when the Ministry of Education and Culture through the TKPK (Education and Culture Communication Technology) project developed a pilot Open Junior High School in 5 (five) pilot locations, namely ( a) West Java Plumbon Open Middle School, (b) Central Java Adiwerna Open Junior High School, (c) East Java Kalisat Open Middle School, (d) Kalianda Open Public Middle School in South Lampung, (e) Terara Open Middle School East Lombok District West Nusa Tenggara Province (Bulletin REASONABLE NTB Dikbud 1997). Open Junior High School is designed as a solution to provide formal education services for students, because a number of factors cannot be accommodated in regular schools. These factors include the geographical location of student residence that is difficult to reach, the reason for the work must be to help parents, and others. Open Junior High School students are basically the same as ordinary junior high school students (regular) but for them are provided a choice of different ways of learning. Open Junior High School curriculum is organized into modules. The module is the smallest unit of teaching material that students can learn independently. The module is the smallest, yet complete unit of teaching material. Each module consists of at least learning objectives, learning instructions, pretest and post test, material, assignments, exercises, up to the final test module and the key answers. The student's task is to complete the modules one by one. Module philosophy is like a step. Each module is one young child, so that after completing one module and working on the final module test by achieving the minimum score criteria, the student can advance to the next module. So on, so that the concerned can complete the entire module and go up to the class.

The development of ICT offers convenience in all aspects of life, including the implementation of long distance open learning system services, along with the growing use of ICTs in various aspects of life, the idea of long distance open education services was born by optimizing ICT utilization. One of them is an ICTbased SMAT that involves a number of concepts and theories that support it. For this reason, in this section, a number of notions of the concepts used in this study must be stated first. Some concepts related to the article in this article include; distance education, open school, primary school, place of learning activities (TKB), and ICT-based learning which is often referred to as elearning 
First, distance education is a concept that refers to the separation of places between students and educators. Long distance shows the understanding that teachers and students do not meet in one place or one classroom as in general schools. In Permendikbud No. 119 of 2014 mentioned Distance Education, hereinafter referred to as $\mathrm{PJJ}$, is education that students are separated from educators and their learning uses various learning resources through the application of the principles of education / learning technology.

Secondly, what is meant by SMA clearly refers to senior secondary level education units as they are generally known, but there are open frills making SMAT different from other high schools. The use of open words refers to the availability of (open) choices related to place, time, and way of learning for students. In other words, students can study anywhere, anytime, and in ways that are appropriate to the individual learning styles of the students concerned. Whereas what is meant by ICT-based is the optimal use of ICT both ICT as a means of learning, learning resources, as well as learning management tools. Theoretical study of open education is always associated with distance education, so the use of its designation is often combined as distance education. However, open learning is not a synonym for distance learning, nor is distance learning part of open learning (Holmberg, 1992). Open learning can occur at a distance, but can also occur in classrooms. While distance learning refers to the distance between students and teachers. This makes students required to have control over the choice of learning strategies.

In Ministry of Education regulationno. 119 of 2014 concerning the Implementation of Distance Education in Primary and Secondary Education, the definition of open school is one form of a formal education unit that stands alone but is part of a mather school that organizes its education using independent learning methods. In this candy also mentioned that Open High School is a form of distance education for secondary school.

Third, what is meant by a mother school is an open school education provider unit. The mother school in addition to carrying out conventional education for regular students, also opens a path of education to open school students. Open school students are enrolled as students at the mother school and fulfill all administrative requirements at the mother school, they also take exams and obtain diplomas from the mother school. For this reason, the mother school organizes open curriculum and administration for students. The mother school can assign a vice principal who handles open student services. Thus, for students to open their differences with regular students is the choice of way, time and place of study.

Fourth, LAC (learning activities center) is a room or place where open school students are regularly scheduled to meet to conduct daily learning activities. LAC is 
usually located close to the center of the student residence. One of the functions of LAC is that students who are far from the main school do not have to go and go home traveling too far to go to the parent school. LAC can be opened by utilizing

available spaces, such as rooms in elementary schools, madrassas, village halls, places of worship such as mosques, churches or others, even residents' houses, etc. the important thing is that the room is adequate as a place for learning activities. In Permendikbud 119 th 2014 stated that LAC is part of an education unit in the form of a place or space that is representative to support the implementation of learning activities.

Fifth, ICT-based learning or often called elearning is a concept that is born in line with the development of information and communication technology. There are many notions of elearning, one of which is Holmes and Gardner that defines elearning very simply, according to him, is learning online access to learning, anywhere, and anytimes. Although briefly formulated, but in that definition what is meant by elearning includes elements; the availability of infrastructure to be able to access on line, the availability of internet networks, the existence of systems or applications, the availability of digital learning resources, and learning activities can be done anywhere and anytime. Elearning is a generic term in the form of many types of learning referred to as elearning as mentioned by Horton, among others; stand alone course, virtual classroom courses, learning games and simulations, embeded learning, blended learning, and mobile learning. All of these terms refer to certain learning designs. Horton reminded of the importance of preparing learning designs before implementing elearing. Learning design provides direction and limits on which elearning will be held, including the selection of authoring tools, management systems, and other technology options. A clear and consistent learning design can help elearning success.

In fact, it is very difficult to apply learning that is fully online. As is the case with conventional face-to-face learning, elearning also has a number of weaknesses. Therefore, learning activities are often combined between online learning activities and offline activities. This mixed learning activity model is known as blended learning or mixed learning activities. However, Uwes Chaeruman reminded that what is called blended learning is not just a mixture of online and off line, but is a combination of four dimensions; synchronous directly (face to face), asynchronous directly (on line), asynchronous independently, and collaborative asynchronous. In learning activities at Open High School, there are two modes of learning activities, namely the activion domon (dominant on line) and domtamu (dominant face to face).

\section{METHOD}


This study is a case study research aimed at getting a comprehensive picture of the concepts and implementation of ICT-based learning in Narmada Senior High School. The results of this research are expected to be a reference material for the application of ICT-based open schools in other places that have the same character as Narmada Senior High School.

The main questions to be answered in this study are; "How does the actual implementation take place in the field in the use of ICT in learning activities in the Narmada SMAT system, both learning activities at the mother school, learning activities center (LAC), and individual learning activities?"

From the main questions above, there are a number of research questions that will be proposed, among others;

1. What is the current condition of ICT-based learning activities at Narmada Senior High School?

2. How does the implementation of ICT-based learning in Narmada Senior High School run as planned?

3. What are the obstacles faced in the implementation of ICT-based learning in Narmada Senior High School and what is the solution?

To get answers to the three questions above, the following research steps will be taken;

1. Literature study which includes the collection of preliminary documents for the design of the SMAT and references related to open distance education.

2. Field data collection through surveys, field visits, and / or interviews with resource persons

3. Deepening research questions (Improvement of research design)

4. Processing and presenting data

5. FGD that involves experts, practitioners, and policy makers related to open distance education services

6. Preparation of reports

This study adheres to a qualitative paradigm, in which the researcher with the subject under study does not stand apart, but is a work partner involved in the development of the SMAT. The study was conducted by a team consisting of the Ministry of Education and Culture as the person who had been involved in the design of the SMAT concept, the co-respondents of ICT activists for education in 
NTB, and the SMAT Narmada ICT manager as the main respondents. With this approach, the results of the study are expected to be more in-depth.

\section{RESULT AND DISCUSSION}

\section{ICT-based Open High School Design}

Narmada Senior High School located at Jl. Suranadi No. 1 Narmada West Lombok, NTB is one of the 6 (six) pilot locations of the ICT-based SMAT which was initiated by the Directorate of Special Education and Special Services (PKLK) of the

Ministry of Education and Culture since 2013 and began opening in the 2014 school year. Other locations are high school Negeri 12 Meringin Jambi, SMA Negeri 2 Padalarang West Java, SMA Negeri 1 Kepanjen East Java, SMAN 3 Sorong, West Papua, and State Senior High School 2 Gambut South Kalimantan.

The SMAT is designed with the optimal use of information and communication technology (ICT), therefore this service is often referred to as ICT-based SMAT. ICT used includes infrastructure, networks, applications, and student learning devices. Every SMAT student is equipped with one tablet computer which has the SMAT elearning application installed and the digital content needed. Modules are no longer in the form of a written book, but are completely digitally embaded on the application. The tablet is connected to a local server at the parent school, so that every time the student's learning progress updates are documented on the system on the parent school server. The master school server is connected to the internet and then can regularly synchronize with the central server in PKLK. Thus the learning progress of each SMAT student can be monitored.

To realize the plan, the PKLK Directorate at that time had cooperated with a number of experts from various competent agencies, including the High School Directorate, Dit SMK, Pustekkom, Seamolec, UT (open university), and a number of vendors who supported this program. The elearning application was developed by Seamolec, while the system model design adopted a remote open learning system that was developed by both Pustekkom and UT. Digital modules are developed by teachers who are experienced in writing open learning materials. Network infrastructure utilizes the national education network (Jardiknas).

The characteristics of SMAT include, among others (exposure to PKLK Directorate, 2014);

- Students can study anywhere, anytime

- Tutorial is done online and face to face 
- Achievement of curriculum targets for each subject is developed with independent modules (learning materials)

- The learning system for delivering modules is done with a web-based distance learning system

- All subjects are prepared by student textbooks and teacher handbooks in the form of ebooks

- Modules are equipped with an independent study guide, questions, enrichment, referrals, and applications

- The academic administration starts from registration until the tutorial schedule is done online

- Final semester exams, national final exams are conducted offline at the parent school

- Complete curriculum with guidance from the best national tutors / teachers

\section{Current Condition of Narmada Senior High School}

Narmada Senior High School is part of the service at the education unit of SMA Negeri 1 Narmada, West Lombok, NTB, where SMAN 1 Narmada is the main school. The parent school is an education unit which is a place where students are registered and will take the exam as students from the school concerned. While the daily learning activities at SMAT take place outside the main school which is often referred to as LAC (place of learning activities).

At the time this research will begin, on August 5, 2018 an earthquake struck Lombok. This earthquake occurred repeatedly in close proximity, resulting in a number of casualties and damage to infrastructure, buildings and houses in a number of areas, including the SMAN 01 Narmada building which also suffered cracks. Therefore, for the time being this research was postponed. On August 27, 2018 we received news from respondents that learning activities at school had begun again even though they were still in a tent. But conditions in general in Lombok have not returned to normal. So the research is resumed according to conditions. Besides getting this information, our respondents also provided preliminary information regarding SMAT in Narmada. The following is a summary of the initial findings.

SMAN 1 Narmada is located on Jl. Suranadi No. 51, Nyur Lembang, Narmada, West Lombok. At this time (2018) there were 164 high school students in Narmada registered in $9 \mathrm{TKB}$. The furthest distance from TKB is $22 \mathrm{KM}$ from the main school with a travel time of approximately 40 minutes using a motorcycle. TKB generally 
hitches a ride in classrooms in public schools, so that all learning support facilities can also take advantage of available facilities, such as tables, chairs, blackboards, even libraries. At least twice a semester they must come to the main school to take the midterm and final exam.

However, the attendance level of students at TKB is still relatively low, around $65 \%$ present per day. Learning activities at TKB are also still dominant face to face, meaning that dependence on teacher attendance is still quite high. The enthusiasm of the participants following the lesson was relatively low, around $65 \%$. Even so, the presence of a good teacher at TKB is quite good. Each subject is taught by a study teacher. The presence of the teachers in TKB is recognized as teaching hours.

Profile of SMAT students is generally from a family of farmers and traders. The daily activities of children outside the learning activities at TKB are to help their parents in the fields, to sell, or to become casual workers on the market. The

general condition of their economy includes underprivileged families. Learning motivation is generally to get a diploma to get a job, the general learning spirit tends to be low.

ICT tools used for learning activities fully rely on the devices provided by the school. In each TKB there is a set of PCs (personal computers) and projectors as a presentation medium for teachers or tutors, while students are equipped with one tablet computer each. The elearning application developed by the center since two years ago (2016) can no longer be used, as well as the tab tools that are shared by the center at the beginning of the SMAT program are launched, can no longer be used. Therefore, the Narmada SMAT manager took the initiative to develop its own application with a new device. The elearning application was developed with a moodle-based LMS (learning management system). The developed LMS is a closed system that is not connected to the central server or other open schools. However, in this system all stake holders such as principals, parents, or education offices can monitor student learning activities at LMS according to their respective authorizations.

The SMAT curriculum is the same as the regular student curriculum. SMAT students must complete a number of the same subjects as regular students. Learning activities at LAC are routine and scheduled. For the needs of digital content and open learning modules, the teachers have been prepared according to their respective fields of study.

In order to get more in-depth information from the main sources, the researchers went to several SMAT students in their homes and interviewed them. The following is a summary of the results of visits from several students who were met. On September 24, 2018, the researcher met one of the Narmada high school students 
named initials RId, class XII, LAC SMP N 3 Lingsar. Everyday RId works odd jobs, building servers, helps parents maintain male chickens in other villages, find vegetables in other people's fields to get a salary, or help his aunt to weave KETA when it's loose. According to RId, how to use a tablet for online teaching and learning is never done with a teacher, Rld forgot how to find subject matter already embedded in the tablet, forget the email address too, BSE material is not on the tablet. RId has WA, FB, and email, but has no internet quota. According to Rld, if there is a tablet quota, it is usually used for games or WA.

In addition to students, researchers also met with the teacher. According to one of the teachers, mentoring assistance and socialization on how to use the tablet is only done when entering the new school year. Students have never been invited to mentor how to use a healthy tablet when students are at home or at LAC. At home, students generally have busy work, such as making handicrafts named KETA, namely woven crafts from rattan in the form of bags, plates or tissue places, the rattan can be expensive items of value. The tools are enough knives, nail clippers, blek used to be classified and plowed. The teacher also never sent assignments to students via email. Based on the schedule of face-to-face learning activities are 3

(three) times a week at LAC, namely Monday, Thursday, and Friday. However, the researcher did not get information about the technical instructions for the teacher and tutor teacher in the management of LAC.

The second student visited by the researcher is Irf. The visit was held on 26 September 2018. According to Irf the use of tablets in learning, sending answers to questions about the subject matter to teachers in the fields of Social Sciences, Arts, Science, Mathematics and Indonesian. If the data package is used up, buy it yourself, "This is what I did when I was in class X, while in class XI, I was no longer active," he said. The e-mail password is forgotten, e-mail also does not remember, so the learning process with the teacher in the parent is broken up. The use of tablets is only for sending answers to questions and WA with friends. Other learning sites have never been visited and even he is not aware of other learning sites. Learning content on tablets is very limited in number, even BSE content is not embedded in the tablet.

In addition to Rld and Irf, researchers also met three other students, respectively Irw, Sab, and Mrz. They are currently sitting in the XII class of Narmada Senior High School. Of the three students, information was obtained about tablet usage, damage occurred, screen blanks, audio offs, broken LCDs, and there were also students who lost their tablets. Teaching and learning activities since the new academic year 2017/2018 are not optimal. Student recognition when the tablet is good is used to send assignments via e-mail to the teacher in the parent, open learning content embedded in the tablet, open UAS questions, etc. But one of the students, Sab, admitted that he did not really understand the use of tablets as a 
learning medium. Tablets are more widely used outside of looking for learning content, for example for WA, FB, playing games, etc.

\section{Usege of ICT}

The initial design of the ICT utilization architecture to support the SMAT system can be seen as the following figure.

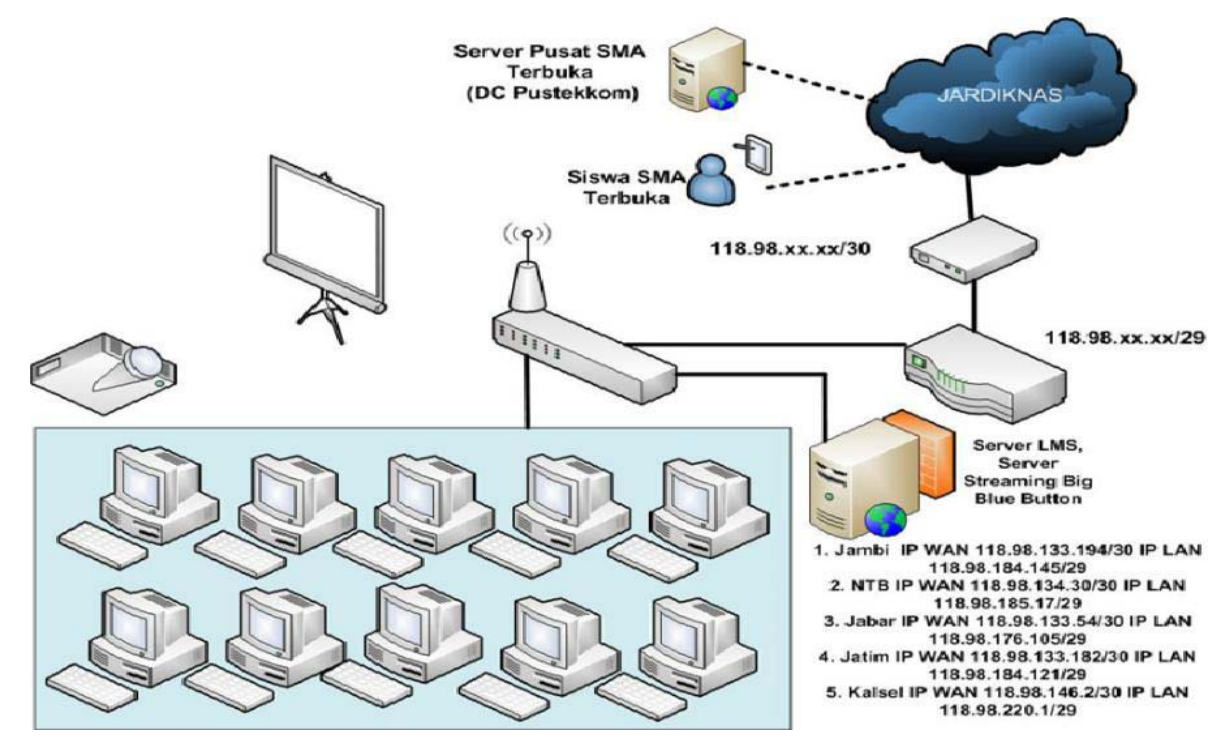

Teaching and Learning System (PBM) conducted in the Open High School program is designed to apply synchronous and asynchronous concepts according to the method chosen in its implementation. There are 3 (three) areas in the management and utilization of the content contained therein, these areas are:

\section{1). Central LMS (Learning Management System)}

The LMS system contains entities such as content, student lists, teacher lists and setting activities and interactions between entities. This system is located in the Ministry of Education and Culture infrastructure which is a PBM service center that can be accessed by all users, both teachers, students or organizers in monitoring the activities that are in it. In addition this system is also connected to the PBM system that is planted on the school server and synchronizes periodically so that it can be used for the teaching and learning process offline in schools.

\section{2). School LMS System}

This PBM system is in the parent school and is connected to the server at the center to synchronize so that the content in the school is always updated 
accordingly so that it can be used optimally by students and teachers. In general, teachers and students can access the LMS server in the center and also in the school. The school system is connected to public access so that it can also be accessed online and offline wherever the teacher and students are. The schoolprepared infrastructure includes the School LMS server, internet access was held initially using VSAT technology, which at present some points have switched to using optical fiber with a bandwidth capacity of 1-2 Mbps, Addressing Public IP to facilitate synchronization and access, Broadcasting cameras to serve synchronous when needed video conferene between teacher and student, LCD and Projector, and Self. The completeness of this device is widely used when students are at the parent school and meet with the teacher at the parent school accompanied by the tutor teacher and can do the teaching and learning process face to face.

\section{3). LMS Mobile System}

PBM systems are planted on mobile devices of students and teachers to facilitate access of teachers and students to carry out PBM activities wherever and whenever because the mobile device / device can be used either on the client or off line. Content can be synchronized either through the system at the Center or School. To be able to use the device in the form of a tablet, it is equipped with a simcard for student connections wherever they are when accessing the LMS system in the school or LMS in the center.

The division of this content area is to provide convenience in organizing especially for regions or schools with limited access and inadequate ICT infrastructure.

The design of the national scale system cannot yet be implemented. Therefore, currently the LMS system in Narmada Senior High School stands alone. The learning system at Open High School is supported by optimizing ICT utilization, in

this case each student is equipped with a tablet computer. This tablet computer has been filled with on-line learning applications (elearning) developed specifically according to learning needs, equipped with learning material content, and learning modules that have been prepared for the needs of self-learning. The tablet is equipped with a modem to connect to the internet, so that students can search and add teaching materials available on the internet at any time, and can schedule online tutorials with their teacher (tutor) on a scheduled basis. They can also participate in online discussion forums. Tablet computers can be taken home by students, so students can study at home or from any place they like. However, scheduled three times a week they must come to LAC to study with tutors and tutors. The final module test or test training facility is available in each module that they can work on their own independently. However, for the midterm and final semester examinations students must come to the main school because the exam is carried out with supervision from the teachers. 
Findings in the field, this system is not running as expected because currently the student tablet computer is no longer connected to the internet.

\section{Problems and solutions}

The main obstacle felt by the parent school as the organizer of the SMAT is the reduction of central management support. At the start of SMAT in Narmada, the central support was very intense, including manager training, ICT engineering training, module preparation training, even MOS (student orientation period) also facilitated by the center, and supported with sufficient operational costs. But in the second year the training was not carried out anymore.

Applications developed by the center do not meet the needs, so the master manager must develop the application by himself. Likewise, the main supporting ICT equipment for open learning is that most tablet computers have been damaged so they have been replaced with new tablets. However, due to operational support that stopped, the tablet computer was no longer connected to the internet. As a result, all online learning activities almost stopped. Current learning is conventional again by relying on scheduled face-to-face activities only three times a week.

\section{CONCLUSION AND SUGGESTION}

Based on the results of this study, some conclusions and recommendations can be formulated as follows.

\section{Conclusion}

The ICT-based Open High School (SMAT) system design was initially implemented very well and comprehensively. ICT devices in the form of tablet computers in which LMS applications have been installed, learning material content, and problem training materials, and are connected to the internet have been running

well, both at the parent school, at LAC, and at student learning activities at home. However, since the beginning of 2017, all of the good processes have decreased, this is due, among other things, to lack of consistent management support, inadequate field preparation, training and technical guidance for managers who are still lacking, and weak monitoring and evaluation systems. and the lack of clarity in the direction of the implementation of the SMAT policy.

Meanwhile, tablet devices are no longer used as a means of learning, teaching and learning activities at LAC (where learning activities) take place conventionally, namely face to face with the teacher. 


\section{Recommendation:}

Based on the results of this study, the following recommendations are presented, including the following;

1. There is a need for consistency in updating content into the LMS as a basic intake of the teaching and learning process so as to facilitate tutors and students in obtaining learning content

2. Ease of LMS application by considering usability factors considering students are beginners in using ICT devices such as tablets

3. Synergy of management management of the administrative system between the center and the region, considering that the assistants / teachers who are assisted get a workload that remembers the task as a teacher and must meet students by penetrating areas with heavy terrain

4. Build Central Access Community (CAP) education that is easily accessible to students by connecting to the LMS system both at school and at the center

5. It is necessary to strengthen the monitoring system both by the center and by the Provincial Education Office

6. Consistency of policy direction is needed in the development of SMAT service delivery

7. Training and technical guidance for the SMAT organizers, including managers, tutors, and tutors.

8.

\section{REFERENCES}

Bielawski, Larry and Metcalf, David, Blended eLearning, Integrating Knowledge, Performance, and Online Learning, HRD Press, Canada, 2003

Borje Holmberg, Theory and Practice of Distance Education, (London: 1992)

Chaeruman, Uwes Anis, Development of Blended Learning System Design Model for Indonesian Spada Program, Desertation, Postgraduate Program of UNJ Jakarta, 2018

Directorate of PKLK, Material Exposing the Concept of Open State High School / K, Supporting Universal Secondary Education, 2014

Holmes, Bryn and Gardner, John, E-Learning, Conception and Practice, Sage Publications, New Delhi, 2006 
Horton, William, E-Learning by Design, Pfeiffer, San Francisco, 2006

Jaka Warsihna, Middle Distance Education as an Alternative to Support Universal Secondary Education, Pustekkom, Teknodik Journal vol. 17 No. December 4, 2013

Macdonald, Janet, Blended Learning and Online Tutoring, Planning Learner Support and Activity Design, second edition, Burlington, 2008

Sadiman, Arief S., Open Middle School, Case Study in Indonesia, UNESCO, Jakarta, 1996

Law No. 20 of 2003 National Education System

PP No. 17 of 2010 concerning Special Service Education 